\title{
Lo público y la libertad en el pensamiento de Julien Freund
}

\author{
Cristián Rojas González \\ Universidad de los Andes, Santiago, Chile. Email: cfrojas@miunades.cl
}

\begin{abstract}
Resumen: Lo privado es visto comúnmente como el espacio de la libertad y los derechos individuales, mientras lo público se observa como el espacio de la dominación política, por esto resulta necesario ver cuál es en realidad la relación que hay entre la libertad y lo público. En este sentido resulta conveniente revisar el pensamiento de autores contemporáneos como Julien Freund, que piensan la libertad y lo público tomando distancia del pensamiento liberal tradicional que ha determinado la visión actual de las dos esferas mencionadas. En Freund lo público es espacio de libertad en el ámbito político, y garantía de libertad para los demás ámbitos de la vida de las personas.
\end{abstract}

Palabras Clave: Público, libertad, Freund, política.

\section{Public realm and freedom in the thought of Julien Freund}

\begin{abstract}
Private is commonly seen as the space of freedom and individual rights, while the public realm is seen as the space of political domination; that is why it is necessary to study what the relationship between freedom and the public realm really is. In this sence, it is appropriate to review the thinking of contemporary authors such as Julien Freund, who think freedom and the public realm taking distance from the traditional liberal thought that has determined the current view of the two abovementioned areas. In Freund public is free space in the political arena, and guarantee for the freedom on the other areas of people's life.
\end{abstract}

Keywords: Public, freedom, Freund, politics.

\section{Pública e de liberdade no pensamento de Julien Freund}

Resumo: O setor privado é comumente visto como o espaço da liberdade eos direitos individuais, enquanto o público é visto como o espaço de dominação política, por isso é necessário ver realmente o que é a relação entre a liberdade eo público. A este respeito, é oportuno rever o pensamento de autores contemporâneos, como Julien Freund, que pensam a liberdade eo público e tomam distância do pensamento liberal tradicional, que levou a visão atual das duas áreas mencionadas. Em Freund o público é o espaço livre na arena política, e garantia de liberdade para as outras áreas da vida das pessoas.

Palavras-chave: Público, liberdade, Freund, política.

\section{Introducción}

Habitualmente la distinción entre lo público y lo privado es relacionada con el liberalismo y remite a los siglos XVIII y XIX, pues a partir de la Ilustración y el ascenso de la burguesía esa identificación de esferas se hizo más relevante. Sin embargo, el mismo Aristóteles desde el comienzo de su "Política" ya anunciaba esta consideración al decir que "cuantos opinan que es lo mismo ser gobernante de una ciudad, rey, administrador de su casa o amo de esclavos, no dicen bien" (Política I, 1252a).

La distinción público-privado había sido esbozada por varios autores previos a los pensadores liberales, pero al ser estos últimos quienes abanderaron en los siglos venideros la teorización de la distinción y su puesta en práctica, lo privado -el espacio de le economía burguesa y los derechos individuales- tomó preponderancia sobre lo público -el espacio del absolutismo monárquico. A partir de entonces lo privado suele recibir una mayor valoración que lo público por ser el espacio de la libertad, en contraposición al espacio de la restricción y la dominación. Para reconsiderar esta postura revisaremos el pensamiento de Julien Freund, filosofo político francés del S. XX, cuya obra sobre "La esencia de lo político" ha sido un gran aporte para la comprensión no sólo de la política, sino de sus conceptos relacionados. Dentro de estos se 
encuentra lo público, sobre el cual nos proponemos analizar su relación con la libertad y poder afirmar que ésta no es exclusiva de lo privado.

Para empezar hay que señalar que Julien Freund dice que la distinción entre lo privado y lo público permite delimitar el dominio de la actividad política pues separa lo político de lo que no lo es, aclarando que el espacio que corresponde político es el espacio de lo público (Freund 1968). Esto se entiende en que lo político no gobierna todas las esencias (religión, ciencia, arte etc.). La relación social propiamente política es la de lo público, mientras las demás relaciones pertenecen al espacio de lo privado (Ibid).

Tenemos entonces que lo público es más homogéneo porque abarca sólo la esencia política, mientras que lo privado abarca todas las demás esencias (Freund 1968). ¿A qué llama Freund esencia? Habla de esencias para referirse a elementos constitutivos de la vida del hombre a los que considera imprescindibles. Dice que la política es una esencia "ya que cualquier hombre nace y vive en el seno de una colectividad política particular con jurisdicción sobre un determinado territorio, lo que significa en una porción del globo delimitada por fronteras y estructurada por instituciones que son los soportes de los particularismos" (Ibid: 48), sin que estemos hablando necesariamente del Estado moderno o algún tipo de colectividad avanzada. Lo mismo ocurre con la economía, la religión, el arte, la ciencia etc. aunque sea en versiones muy rudimentarias.

Así mismo lo político tiene una esencia propia que está determinada por 3 presupuestos, entendiendo presupuesto como "la condición propia constitutiva y universal de una esencia" (Freund 1968: 101), es decir, conceptos que nos permiten entender por qué la política es política y no otra cosa. Estos presupuestos son: la relación del mando y la obediencia, la de lo público y lo privado, y la de amigo y enemigo (Ibid). Las dos primeras serán de especial importancia en nuestro análisis. De la primera podríamos empezar diciendo que hace referencia a la dominación y a primera vista a la limitación de la libertad, y puesto que lo púbico es el espacio de lo político, sería el espacio de la dominación. En contraposición lo privado suele entenderse como el espacio de la libertad, allí donde cada quien puede elegir sus creencias, sus actividades, sus propias normas, sus propias asociaciones y relaciones sociales etc. Sin embargo a partir del propio Freund explicaremos como la existencia de la esfera pública es garantía de la libertad.

Para alcanzar este propósito empezaremos por analizar la noción de libertad en Freund, y posteriormente nos adentraremos en su concepto sobre lo público.

\section{Aproximación a la noción de libertad en Julien Freund}

Freund no se dedica en concreto al concepto de libertad ni lo trata de manera extensa, pero en su obra puede verse que considera que la libertad existe porque no hay un determinismo global y el hombre debe tomar decisiones sobre determinaciones parciales de todo orden: físico, biológico, político, económico etc. (Freund 1968). El hombre, a diferencia de los animales, es libre por su capacidad de decidir sobre tales determinaciones. Por ejemplo, frente a la sensación de hambre el hombre puede abstenerse de comer para bajar de peso, ahorrar dinero, o por una piadosa práctica del ayuno, mientras el animal sólo tiene la opción de buscar saciar su hambre ingiriendo alimento.

Freund presenta esta situación con el ejemplo del amor -o el enamoramiento-: "No escogemos amar, pero un día nos sorprendemos queriendo, y este sentimiento ha nacido en nosotros, a pesar de nosotros. En el momento en que tomamos conciencia de este amor es cuando tenemos que ejercer nuestra libertad, sea escogiéndolo y concediéndole todas las posibilidades de desarrollo, si el sentimiento es recíproco, sea luchando contra él y rechazándolo si por razones religiosas, morales, familiares u otras, creemos que tenemos que renunciar al mismo" (Freund 1968: 391). Entendemos así que la libertad aparece sólo donde existe un determinismo -“dónde una realidad está determinada” (Ibid: 32) -y consiste en aceptarlo u oponérsele.

Lo que Freund llama determinaciones, obligaciones o necesidades, podemos relacionarlo con la distinción medieval de los "actos humanos" y "actos del hombre" (García-Huidobro 2002). En los primeros interviene la libertad y el hombre hace una elección, mientras que los segundos simplemente ocurren en nosotros sin participación de la voluntad humana. El ejemplo del hambre o el amor -en términos de Freundes el caso de "actos del hombre" que nuestro autor llama determinaciones, pero el ayuno o el rechazo del 
amor involuntario son "actos humanos" en los que se ejercita la libertad. Las determinaciones, sin embargo, no deben pensarse sólo como "actos del hombre" pues pueden referirse también a situaciones que ocurren fuera de él pero que lo interpelan en ámbitos tan diversos como las condiciones meteorológicas o las tensiones sociales.

Si vemos el relato de Heródoto sobre la Segunda Guerra Médica (Historias VII, 222), encontramos tres situaciones sobre la libertad frente a la determinación de la invasión persa. El grueso de las tropas griegas "Los Aliados"- abandonaron las Termópilas con la autorización de Leónidas, y sólo permanecieron junto a él los tebanos y los tespieos. Los primeros estaban obligados a quedarse contra su voluntad en calidad de rehenes, mientras los segundos estaban allí por decisión propia, dispuestos a dirigirse a la muerte frente a las tropas de Jerjes. Observamos, en primer lugar, que la mayoría decidió abandonar la campaña libremente. En un segundo momento están los tespieos de quienes dice Heródoto que se quedaron "con absoluta libertad" (Historias VII, 222) poniéndose bajo las órdenes del Rey de Esparta. Son dos maneras de afrontar la determinación siendo ésta no el límite de la libertad sino su oportunidad de ejercicio, incluso en el caso de los tespieos que decidieron someterse a la autoridad militar, asumir la responsabilidad de la guerra y encaminarse a una muerte segura.

De los tebanos - tercera situación-, aunque eran rehenes y su condición no es el paradigma de la libertad, podría pensarse que usaron su libertad frente a esa determinación, por lo menos en la opción de no asumir las consecuencias de desobedecer a Leónidas, o en el rechazo en conciencia a las decisiones de los espartanos. Pero sobre la opresión y la libertad de crítica hablaremos más adelante.

En síntesis Freund dice que "La libertad no se define, ni muchísimo menos, por una ausencia de obligación o determinación; es la manera con que utilizamos, bajo la entera responsabilidad de nuestro juicio, la necesidad, la obligación y las determinaciones" (Freund 1968: 392). Y es desde esta perspectiva que Freund critica la idea kantiana de oponer naturaleza y libertad, así como la oposición que se hace habitualmente entre libertad y sociedad (Freund 1968).

En el primer caso - no ahonda en esto- debe referirse al pensamiento derivado de la tercera antinomia de la razón pura de Kant en la que plantea: “Tesis: La causalidad según leyes de la naturaleza no es la única de la que se pueden derivar los fenómenos todos del mundo. Para explicar éstos nos hace falta otra causalidad por libertad. Antítesis: No hay libertad. Todo cuanto sucede en el mundo se desarrolla exclusivamente según leyes de la naturaleza" (Krv, A 445 B 473). Se entiende a primera vista que contrapone la causalidad por libertad a las leyes de la naturaleza, y Freund no acepta que la libertad requiera ausencia de necesidad o determinación.

En cuanto a la oposición entre libertad y sociedad se asume que hace referencia a perspectivas como la del anarquismo de P. J. Proudhon, por lo menos frente a un concepto de sociedad que implica necesariamente la jerarquía, el ejercicio del gobierno etc. (Proudhon: 1968) En último término una sociedad política. Así mismo se refiere a tesis sobre el estado de naturaleza del hombre en libertad antes de la vida en sociedad, las cuales no comparte pues la condición de la libertad no es la falta de determinación.

A esto hay que añadir que en “¿Qué es la política?” (Freund 2003) Freund deja en claro que la libertad no es un propósito específico de la política pues también es una pretensión del arte, la religión, la ciencia o la moral, aunque debe haber condiciones políticas de la libertad de los individuos como es la existencia de una autoridad reglamentaria. Además no considera que la libertad política difiera formalmente de la libertad en general (Freund 1968), y agrega que "la política no es la única que se propone contribuir al fortalecimiento de la libertad en el mundo: incluso puede privarlo de ella" (Freund 2003: 11). Acá se hace presente la pregunta fundamental en este trabajo- de si la política puede suprimir la libertad desde lo público, o si acaso lo público es un espacio de garantía de la libertad.

Habiendo observado la noción de libertad en Freund, podemos ver su relación con el concepto que tiene el mismo autor sobre lo público.

\section{La noción de lo público en Freund y su relación con la libertad}


Dice Freund que "mientras exista una sociedad, que forzosamente será siempre política, la vida humana quedará dividida en dos partes: por una parte en la vida pública, porque el hombre pertenece inevitablemente a una unidad política, y por otra, en vida privada, porque mantiene con sus semejantes relaciones de reciprocidad y asociación" (Freund 1968: 364). Así, puesto que las esferas de lo púbico y lo privado parecen ser conjuntamente exhaustivas y mutuamente excluyentes, es útil partir de la noción de lo privado para delimitar lo público.

\section{Lo privado}

Para empezar hay que decir que "existe una verdadera y constante interpretación de las dos esferas, y de ahí los conflictos y confusiones" (Freund 1968: 367), pues la preponderancia de una u otra doctrina política pueden hacer variar las categorías. Por ejemplo, el socialismo suele tener una consideración más amplia de lo público por extender las funciones del Estado a la salud, la educación, y en general la seguridad social, mientras que el liberalismo busca llevar los límites del Estado a sus mínimos posibles.

También puede darse cierta confusión sobre lo que es propio de lo privado cuando la política se mezcla con la religión, como ocurre en casos que van desde la derecha republicana en Washington hasta la izquierda chavista en Caracas, o cuando el arte asume contenidos políticos como el muralismo de Diego Rivera en México o la trova de Silvio Rodríguez en Cuba, o incluso cuando la ciencia estuvo al servicio de los grandes bloques de la Guerra Fría para mantener el equilibrio nuclear, entre otros innumerables casos. Sin embargo, para Freund nunca son estas esencias directamente políticas, sino sólo de manera secundaria (Freund 1968). Y en caso de que, por ejemplo, una lucha religiosa invada el dominio de lo político asumiendo sus propósitos en cuanto a la existencia y unidad de la colectividad, entonces se convertirá en una lucha política (Ibid), como el caso de la lucha del Talibán en Afganistán contra la Liga del Norte, o el caso de la revolución iraní encabezada por los ayatolás.

No obstante estas confusiones o debates que pueden presentarse, hay unos rasgos permanentes de lo privado. Lo privado no es sinónimo de individual pues se refiere al individuo "en el conjunto de relaciones en el seno de las cuales no es más que un individuo entre otros" (Freund 1968: 384). Es así como lo privado se refiere al individuo en la sociedad y no en soledad, pero en las mencionadas esencias que no pertenecen a lo político, tales como la religión, el arte, o la ciencia. Lo privado es una esfera altamente heterogénea que representa el límite negativo de lo político (Ibid). Lo privado, además, divide, excluye, pero en principio también permite la libre adhesión o la libertad de retirarse del grupo. Por ejemplo, ocurre con agrupaciones tan disímiles como un club de pesca, una tribu urbana, una iglesia, un club de fans, una hinchada de fútbol etc. Es por esta razón, entre otras, que la modernidad ha presentado el espacio de lo privado como el guardián de la libertad.

Freund no acepta esta última consideración, pues se basa en el supuesto de que la determinación corresponde al espacio de lo público y no al de lo privado donde se viviría la libertad, pero -como ya vimospara Freund la determinación no significa el límite de la libertad sino su oportunidad de ejercicio. En realidad para Freund lo público es necesario para garantizar la libertad, y no sólo la libertad política sino la libertad de las demás esencias. Para entender esto entraremos directamente a la noción de público en Freund.

\section{Lo público}

Normalmente se entiende por público "lo que concierne a todo el mundo indistintamente, lo que está abierto a cualquiera, lo que se hace a la luz del día, al descubierto, y que todo el mundo puede enjuiciar" (Freund 1968: 395). Freund habla de cuatro acepciones relacionadas con esta concepción: lo que se refiere a la cosa pública, en términos modernos el Estado y sus instituciones, también el sentido de colectividad, pueblo o comunidad social, y el público como conjunto de personas reunida en un lugar -el público de un teatro-, o diseminado -el público literario- (Ibid). Estos dos últimos no tienen un sentido político aunque con los primeros comparten rasgos como la ausencia de discriminación. 
Para precisar Freund analiza lo público desde el exterior observando que no se trata de un simple colectivo (Freund 1968). Esto ya había sido anunciado por teorías como la de la voluntad general de Rousseau, que no es equivalente a la voluntad de todos. Dice Rousseau que "hay mucha diferencia entre la voluntad de todos y la voluntad general: esta solo mira al interés común; la otra mira al interés privado, y no es más que una suma de voluntades particulares, pero quítense de estas mismas voluntades el más y el menos, que se destruyen mutuamente, y quedará por suma de las diferencias la voluntad general" (Rousseau 2008: 50). En definitiva, lo público no es un simple cúmulo de personas y voluntades.

Esta idea permite a Freund observar que desde el interior lo público es unidad impersonal. Es unidad porque una colectividad política es ante todo una unidad política (Freund 1968). Lo público sería "el soporte de un orden común, que trasciende el pluralismo interno y le da la posibilidad de mantenerse desarrollándose sin demasiados golpes ni choques" (Freund 1968: 399), y es en este sentido como nuestro autor entiende las palabras de Aristóteles cuando dice que "el lugar de la ciudad, en efecto, es uno determinado, y los ciudadanos tienen en común una misma ciudad” (Política II, 1261a). Además de tener unidad es impersonal porque es exterior y superior a los individuos: lo público es relación impersonal.

Al ser impersonal lo público necesita ser representado, pues aún cuando la colectividad pudiera tomar decisiones no podría ejecutarlas. De esta forma puede haber representación en la toma de decisiones, y siempre hay representación en la ejecución manteniendo el sentido impersonal, pues "la gestión administrativa es un acto público, es decir, el funcionario es sólo empleado, no es el dueño de lo público, ya que de otra manera se llegaría al absurdo de que los demás ciudadanos serían sus súbditos" (Freund 1968: 406). Así no sólo representan las asambleas legislativas sino también un solo individuo, incluido el monarca, que en último término no tiene un poder irrevocable - como ya lo ha dejado en claro la historia- pues toda representación se basa en una convención que puede disolverse.

Otra característica de lo público frente a lo privado es la homogeneidad. Esta se entiende "no en el sentido de uniformidad intrínseca de los miembros, sino el de una regularidad exterior” (Freund 1968: 414), que está es introducida por el derecho. El derecho no se refiere al individuo sino a las relaciones entre individuos, es social por naturaleza y por lo tanto lo público supone el derecho (Ibid). Es así como "cualquier sociedad política por el hecho mismo de implicar una esfera pública, se halla constituida, pues de otro modo no sería política... lo que significa que el espacio de lo público por su propia naturaleza implica una constitución por rudimentarias y toscas que sean las disposiciones que reglamentan la forma del poder, el principio de sucesión, las relaciones entre los miembros de la colectividad y la autoridad, etcétera." (Ibid: 422) Sólo así existe lo público. Esto ya lo esbozaba Aristóteles cuando afirmaba que "es necesario introducir una organización política tal que los ciudadanos, partiendo de los regímenes existentes, sean fácilmente persuadidos y puedan adoptarla en la idea de que no es tarea menor reformar un régimen que organizarlo desde el principio" (Política IV, 1289a).

¿Qué relación tiene esto con la libertad? Dice Freund que "Las reglas del derecho tejen toda clase de relaciones entre los miembros de la sociedad, obligando a unos a respetar a los otros, por lo menos exteriormente, armonizando en todo lo posible las distintas asociaciones y grupos, y determinando su área de rivalidad, de manera que las relaciones en el seno de la colectividad no son las de simple coexistencia, sino las de un régimen común y, a veces, de un sistema jerárquico reconocido como valedero por el conjunto" (Freund 1968: 418). Esto es importante pues vemos que en principio el derecho limita la arbitrariedad y por lo tanto impide la supresión injustificada de la libertad, lo cual nos permite considerar lo público como espacio de libertad opuesto al estado de naturaleza de Hobbes. "En efecto, a veces ocurre que una sociedad cae en una especie de anarquía que rompe la unidad y torna caduco el derecho, pero al mismo tiempo, también lo público se desgasta, destrozado como una presa por bandas rivales" (Ibid: 419), en tal situación no puede garantizarse un nivel justo de libertad.

En este punto Freund habla también de la arbitrariedad que procede no sólo de los particulares sino del mando, y se refiere a la desobediencia antes sus excesos y defectos: "No hay duda de que las irregularidades cometidas por los representantes de lo público son infinitamente más dañinas para el Estado que la desobediencia política de los ciudadanos, que la mayoría de las veces es consecuencia de aquellas, pues ponen más directamente en peligro la estabilidad y la unidad" (Freund 1968: 421). Para mantener su naturaleza 
política el mando debe actuar en lo público, "un mando que sea ejercido fuera de lo público, no tiene ya nada de político" (Ibid).

Para entender mejor este asunto tan relevante en nuestro análisis, vale la pena detenerse en la consideración del primer presupuesto de la esencia de lo político en Freund: la relación entre el mando y la obediencia.

\section{La libertad en el presupuesto del mando y la obediencia}

En primer lugar hay que decir que la sociedad tiene un carácter económico, religioso etc. pero es política en virtud de la relación mando y obediencia que tiene lugar en el espacio de lo público. ¿Qué entiende Freund por mando?

\section{El mando}

Freund entiende el mando como la "relación jerárquica que se establece en el seno de un grupo por la potencia que una voluntad particular ejerce sobre las voluntades particulares, modelando así la cohesión del grupo" (Freund 1968: 129). El jefe es quien posee la prerrogativa del mando.

Lo que llama potencia lo define a partir de Max Weber: "Es la probabilidad de hacer triunfar en el seno de una relación social, a pesar de las resistencias, su propia voluntad, sin importar mucho sobre qué se apoya esa probabilidad" (Freund 1968: 169). En pocas palabras la define como una voluntad que se ejerce sobre otras voluntades haciendo ceder la resistencia y unificando al grupo.

En cuanto a los propósitos del mando, estos coinciden con los propósitos de la política, es decir, la cohesión social por una concordia y paz interior y protección frente a la amenaza exterior (Freund 1968). Cómo conseguirlo, bajo qué formula, no es el tema que más preocupa a Freund, pero podemos imaginar el concepto en nuestro propio contexto en el ejercicio del gobierno del Estado. Sin embargo, Freund no considera al Estado como conditio sine quanon de lo público (Freund 1968), por eso también podemos imaginar el mando en una sociedad primitiva, tribal, un clan etc.

Lo que nuestro autor llama "poder" se relaciona con el mando sin ser términos intercambiables. El poder es "el mando estructurado socialmente en funciones jerárquicas y llevado por una varias capas sociales, variables según los regímenes" (Freund 1968: 130). En esto se entiende que se refiere al aparato formal que hace efectivo el mando.

La existencia del mando no supone necesariamente la supresión de la libertad pues éste es entendido como una determinación, y como hemos visto Freund no ve incompatibilidad entre libertad y determinación, al contrario, es ante la determinación que la libertad se hace presente. Tampoco anula la libertad el mando por la consideración de que se basa en la voluntad personal, pues esto no quiere decir que sea pura arbitrariedad aunque si tiene una propiedad discrecional que se ha entendido en la noción de soberanía, que Freund entiende según Jean Bodin como la "potencia absoluta y perpetua de una república" (Freund 1968), definición a la que adhiere si no se tienen en cuenta explicaciones posteriores de Bodin. La soberanía es potencia absoluta en tanto que no está sometida a leyes sino que las crea y deroga, y perpetúa en tanto que no es periódica ni intermitente.

¿Hasta dónde puede llegar esta discrecionalidad o la soberanía? Por defecto el mando mismo se pierde cuando -como señala Hobbes- la potencia deja de asegurar la protección y por lo tanto cesa la obediencia (Freund 1968). Lo que se ve afectado acá es la autoridad entendida como "aptitud de mostrarse a la altura de las tareas que comporta la función que desempeña" (ibid: 129). Sin el fin de la protección el mando se convierte en gozo personal y pierde la potencia que le permite mantenerse. El mando no puede ser gozo personal, esa perspectiva es, según Freund, el gran error de Calices frente a Sócrates en la conversación presentada en el Gorgias de Platón (Ibid). En realidad "el mando es una voluntad individual al servicio de una colectividad" (Ibid: 134). 
Freund, en cambio, no señala específicamente cuáles son los límites del mando por exceso, lo cual es un punto central en la relación entre libertad y política. Lo que si dice es que la política es dominación del hombre por el hombre y en todos los casos el mando va acompañado de la represión, de la cual el poder político siempre ha querido ser el único depositario legítimo (Freund 1968). Se entiende así lo público como espacio de represión, pero no de supresión de la libertad.

Con el propósito de observar el asunto de la represión -que puede arrojar luces sobre la relación entre la libertad, la política y lo público- pasaremos a revisar la otra cara de la moneda para analizar lo que dice Freund sobre la obediencia. Antes de esto, adelantamos que Freund ve con reservas el adoctrinamiento como recurso del mando -añadiendo que el mando no tiene vocación directamente pedagógica-, pues considera que a veces no se limita a modificar las relaciones entres los seres sino que busca cambiar a los seres mismos. Señala que "una de las características de la tiranía es la de procurar adueñarse del hombre en nombre de la política, bajo el pretexto de guiarlo o salvarlo; lo que no significa otra cosa que adoctrinarlo y someterlo al poder" (Freund 1968: 175). Allí esboza un exceso del mando que puede chocar con la libertad de los hombres. Para entender esto hay que avanzar hacia el concepto de obediencia.

\section{La obediencia}

Para Freund la obediencia es "el acto que consiste en someterse en interés de una actividad común determinada, a la voluntad de otros para ejecutar sus órdenes o bien para conformar la conducta con sus reglamentos" (Freund 1968: 185). La tarea de la obediencia es ejecutar en concreto el acto que conduce a alcanzar los propósitos de la política. La obediencia es "desde el punto de vista conceptual, acto, en posición con el mando, que pertenece a la esfera de lo posible y de la virtualidad" (Ibid: 188). El mando sin la obediencia es como si el emperador chino Qin Shi Huang lanzara un grito de batalla a sus 8000 guerreros de terracota. El mando por sí mismo no puede alcanzar sus propósitos, depende de la obediencia.

Sabemos que desde la perspectiva de Freund la obediencia no supone perder la libertad, pero el autor insinúa límites del mando con respecto de la libertad cuando dice que "el mando que se muestra tiránico rebaja la obediencia al rango de servilismo" (Freund 1968: 185), y aunque no define la tiranía, habíamos visto previamente que considera como una de sus características el procurar adueñarse del hombre. Y añade que "cualquier doctrina del mando que procure reforzarlo o aflojarlo pone correlativamente en juicio el fenómeno de la obediencia" (Ibid: 186).

Entonces, si asumimos que la pretensión de adueñarse del hombre significa la supresión de su libertad, tenemos que la tiranía tiende a suprimir la libertad del hombre. Si con esto la tiranía desdibuja la naturaleza del mando y correlativamente la naturaleza de la obediencia, tenemos que la tiranía se opone a uno de los presupuestos de lo político y desvirtúa el espacio de lo público. De esto podemos concluir parcialmente que el presupuesto de mando y obediencia no puede hacer desaparecer la libertad sin anularse él mismo, y por consiguiente hacer desaparecer lo político de lo cual es condición esencial. Para avanzar en esta proposición analizaremos las posibilidades de la desobediencia como ejercicio de la libertad.

\section{La desobediencia}

Uno de los puntos determinantes de éste análisis está en reconocer cuáles son los límites de la obediencia o las posibilidades de la desobediencia, pues nos permite saber cuándo hay tiranía o cuándo estamos ante una doctrina que procura reforzar el mando de manera excesiva. En cuanto a esto Freund considera que los límites de la obediencia dependen de la casuística, son circunstanciales y por lo tanto no se pueden sentar parámetros universales (Freund 1968). Sin embargo es un tema fundamental en política puesto que la desobediencia no es una situación excepcional, "nace de la inadecuación entre el significado y la intención, reales o supuestos, del mando y los que los ejecutores quieren dar a su acto de obediencia" (Freund 1968: 206). Puede darse ante la oposición frente a la propiedad privada de los medios de producción, la reivindicación de las particularidades étnicas frente a una cultura hegemónica, y un sinnúmero de posibilidades más, siempre en el espacio de lo público. 
En esto vemos que la desobediencia existe por el ejercicio de la libertad. Como ya dijimos, según la visión de Freund la libertad aparece allí dónde hay un determinismo, y consiste en aceptarlo u oponérsele. En este caso el mando es el determinismo y la desobediencia significa el ejercicio de la libertad para rechazar el mando o alguno de sus postulados. Esto es siempre posible, incluso cuando estamos en una situación de aparente supresión de la libertad. Tal es el caso de los tebanos, de quienes dijimos que habrían podido usar su libertad aunque fueran prisioneros de Leónidas y estuvieran obligados a pelear contra los persas, pues podían resistirse a sus mandatos y asumir, libremente, las consecuencias. Dice Freund al respecto: "En el fondo siempre hay un medio para desobedecer aun bajo la más terrible opresión, con tal que se tome el partido de aceptar la muerte antes que ceder" (Freund 1968: 207).

Así, la desobediencia es ejercicio de la libertad y es siempre posible, "es, pues, una perogrullada decir que no hay nunca obediencia total y absoluta" (Freund 1968: 207). Incluso Freund lanza una sentencia que está en la médula de nuestro análisis: "No hay política sin enemigo, pero tampoco sin desobediencia real o virtual" (Ibid). Eso implica que si la desobediencia es ejercicio de la libertad y es presupuesto de lo político, el espacio de lo público supone siempre algún grado de libertad y es el espacio donde tienen lugar las 3 partes o manifestaciones básicas de la desobediencia: la rebelión, el derecho de resistencia y la libertad de crítica.

En conclusión, podemos decir que la relación de mando y obediencia, que tiene lugar en lo público, no supone el fin de la libertad pero si supone su existencia. En este sentido debe permanecer algún grado de libertad en el espacio de lo público o este desaparecería. Podemos entender entonces que público no es contrario a la libertad, y además garantía de la libertad misma. Para reforzar esta segunda afirmación podemos ver lo que piensa Freund sobre el totalitarismo.

\section{El totalitarismo como supresión de lo público}

El mejor ejemplo del sistema de dominación (de la relación mando y obediencia) que más se acerca a la supresión de la libertad es el totalitarismo. Freund lo entiende como "un gigantesco esfuerzo por borrar la distinción entre lo individual y lo público, por eliminación de esta realidad intermedia entre lo público y lo personal, que es la sociedad civil" (Freund 1968: 371). La sociedad civil entendida como el lugar donde lo privado y lo público se interpelan constantemente en compromisos y tensiones. De esta manera cuando la distinción entre lo público y lo privado se elimina, desaparece la libertad política: "sólo hay libertad política en un sistema que respeta la distinción entre lo público y lo privado" (Ibid).

A diferencia de lo que podría pensarse, para Freund el totalitarismo no ocurre cuando lo público suprime lo privado sino al contrario. El totalitarismo "esclaviza el Estado, lo reduce a un simple aparato de ejecución, porque lo despoja del monopolio de la violencia legítima, porque menosprecia el orden jurídico y porque transfiere la violencia y el derecho al partido único y, más exactamente, al jefe del partido que actúa en su nombre" (Freund 1968: 373). En este sentido el totalitario no es el Estado sino el partido, y entonces la libertad se pierde porque lo privado absorbe lo público: ahora la voluntad política soberana es la del partido por intermedio del autócrata. (Ibid) El partido va más allá de lo político y pretende realizar sus ambiciones en las demás esencias (religión, arte, economía, ciencia) adueñándose así del hombre. Esclavizar al Estado es esclavizar a los hombres. (Ibid)

Lo público debe permanecer fiel a su naturaleza, pues "la libertad exige un Estado o institución pública, poco importa su nombre, y sucumbe en cuanto se estatiza o politiza toda la sociedad; exige también instituciones privadas, y sucumbe si se privatizan todas las relaciones sociales" (Freund 1968: 393). Esto confirma que lo público es garantía de la libertad de los ciudadanos.

\section{El ciudadano libre}

El hombre se entiende en todas las esencias que hemos venido mencionando y que el totalitarismo pretende controlar, así que su vida está ampliamente determinada por el ámbito privado. Sin embargo, el hombre no es sólo persona privada sino también ser público: es ciudadano (Freund 1968), que para Freund está estrechamente unido a la noción de libertad como se mostrará a continuación. 
Habitualmente se considera que el sujeto de lo público es el pueblo, como lo hace Hobbes en su $D e$ Cive, cuando distingue al pueblo de la multitud sin orden y lo llama persona pública (Freund 1968). Así mismo se expresa Carl Schmitt en una definición apropiada por Freund: "El pueblo es un concepto que sólo tiene existencia en la esfera pública. El pueblo no se manifiesta sino dentro de lo público y es el que, en general, lo establece. Pueblo y público van a la par: no hay pueblo sin lo público, no hay lo público sin el pueblo" (Ibid: 455). No obstante, también es considerado como sujeto de lo público la persona individual que es llamada ciudadano, y que Freund entiende a partir de Bodin como "aquel que goza de la libertad común y de la protección de la autoridad" (Ibid: 456), y considera que no existe ciudadano sin libertad, sin disfrute de derechos cívicos, pues donde no existe la libertad, no existen derechos (Ibid: 457). El ciudadano, sujeto de lo público, tiene como condición necesaria la libertad.

Para concluir este apartado es importante añadir una cita de Freund en la que reafirma nuestro sentido de lo público como espacio para garantizar la libertad, relacionando al ciudadano, la desobediencia y la libertad: "la desobediencia no puede, llegado el caso, justificarse, salvo si la autoridad es realmente incapaz de garantizar la protección de los ciudadanos, o bien si anula otro elemento fundamental y dialéctico del concepto de autoridad: el de la libertad" (Freund 1968: 457). El espacio de lo público donde actúa el ciudadano y tiene lugar lo político -que tiene como presupuesto el mando y la obediencia- no sólo es compatible con la libertad sino que supone su protección y es necesario para garantizarla.

\section{Consideraciones finales}

Para finalizar es necesario hablar del resultado de la dialéctica de lo privado y lo público que para Freund es la opinión. Él entiende la opinión como "la adhesión a un pensamiento o un conjunto de pensamientos (doctrina) cuya certidumbre no depende de las pruebas incontestables lógicamente, o verificables objetivamente, ni tampoco de una evidencia que se imponga con una veracidad intrínseca. Puede, sin embargo, justificarse con buenas razones; también puede ser pensada o presentarse como una tesis crítica, pero de igual modo tratarse de un error, un prejuicio, una creencia de buena fe o una presunción" (Freund 1968: 461). Es decir, una opinión no se basa en la certeza de un postulado de tipo científico o de evidencia plena, al contrario puede tener una base más o menos sólida y ser incluso errada.

"La política es cuestión de opinión" (Freund 1968: 461), pues no está basada en una especie de método científico aunque algunas ideologías han pretendido llevarla a categorías de la ciencia con teorías últimas incontrovertibles. Esto no significa que cualquier doctrina tenga el mismo valor como postulado, pues no todas resultan de una reflexión rigurosa, un conocimiento amplio del hombre y del mundo etc. Por supuesto la política no solo se trata de la teoría pues la experiencia tiene un importante peso, y podríamos calificar la política como arte práctico (Ibid).

Lo importante para nuestro caso es entender que la variedad de opiniones es inagotable, por esto las ideas similares suelen agruparse para alcanzar objetivos comunes: es lo que ocurre con los partidos políticos y otros tipos de asociaciones. Esto se da porque no puede haber unanimidad en las sociedades, como lo reconocer incluso Rousseau a pesar de su tesis de la voluntad general. Rousseau dice que "Toda sociedad política está compuesta por otras sociedades más pequeña, de distintas especies, de las cuales cada una tiene sus intereses y sus máximas" (Freund 1968: 481). Por supuesto cada facción o partido político busca el triunfo de su opinión para llegar al poder (Ibid), por lo tanto se observa que "todas estas formaciones son asociaciones de carácter privado, pero con vocación pública, y en este sentido la opinión aparece como constitutiva de la dialéctica entre lo público y lo privado". (Ibid: 483)

Como vemos el espacio de lo público es fundamental para la opinión aunque ésta parta del ámbito privado. Dice Freund que "cuando la relación pública no está fuertemente estructurada, las divisiones de la opinión no lo están tampoco, y constituyen más bien clanes, pandillas, o comités de notables. Por el contrario, si la esfera de lo público se halla fuertemente organizada, se ven también aparecer formaciones o partidos políticos en el sentido propio de la palabra, cuyas estructuras se amoldan a las del poder" (Freund 1968: 480). En esto se entiende que lo público determina la posibilidad de que realmente la opinión de los ciudadanos haga parte de la política en la sociedad y de que tenga oportunidad de participar del poder. Así mismo hemos 
visto que la salvaguarda del espacio de lo público permite que ninguna de estas asociaciones de carácter privado -como los partidos- puedan suprimir la libertad política y las demás esencias del ámbito privado. Por esto podemos afirmar una relación entre la lo público y la libertad para la opinión en dos sentidos: lo público protege la posibilidad de desarrollar una opinión, y también permite que está tenga oportunidades de expresarse en sociedad y aspire así al poder.

Como hemos visto, lo público es el espacio donde tiene lugar lo político y por lo tanto también la relación de mando y obediencia. Sin embargo no se opone a la libertad pues ésta no se entiende como ausencia de determinación sino en la manera como abordamos las determinaciones. En este sentido lo público es el espacio de la obediencia que no implica supresión de la libertad, pero también es el espacio del ciudadano libre, de la desobediencia y de la opinión que sustenta también la libertad de crítica. Es lo público garantía de libertad frente a la tiranía y el totalitarismo. Por esto podemos concluir que lo público no se opone a la libertad, al contrario, es para la libertad condición necesaria.

\section{Bibliografía}

Aristóteles (2007) Política, Gredos, Barcelona.

Freund, J. (1968), La Esencia de lo político, Editora Nacional, Madrid.

Ídem (2003), ¿Qué es la política?, Struthart \& Cia, Buenos Aires.

García-Huidobro, J. (2002) Una introducción a la tradición central de la ética, Palestra, Piura.

Heródoto (2007) Historias, Gredos, Barcelona.

Kant, I. (2002) Crítica de la razón pura, Tecnos, Madrid.

Proudhon, P. (1968) Teoría de la contribución, B: Carranza, Madrid.

Rousseau, J. (2008) El contrato social, Maxtor, Valladolid. 